Abstracta Iranica Abstracta Iranica

Revue bibliographique pour le domaine irano-aryen

Volume 29 | 2008

Comptes rendus des publications de 2006

\title{
The military architecture of ancient Choresmia. Paris, de Boccard, 2006, 259 p. (Persika, 7)
}

\section{Étienne de La Vaissière}

\section{OpenEdition}

1 Journals

Édition électronique

URL : http://journals.openedition.org/abstractairanica/25352

DOI : 10.4000/abstractairanica.25352

ISSN : 1961-960X

\section{Éditeur :}

CNRS (UMR 7528 Mondes iraniens et indiens), Éditions de l'IFRI

\section{Édition imprimée}

Date de publication : 15 mai 2008

ISSN : 0240-8910

\section{Référence électronique}

Étienne de La Vaissière, «The military architecture of ancient Choresmia. Paris, de Boccard, 2006, 259 p. (Persika, 7) », Abstracta Iranica [En ligne], Volume 29 | 2008, document 52, mis en ligne le 15 septembre 2008, consulté le 26 septembre 2020. URL : http://journals.openedition.org/abstractairanica/25352 ; DOI : https://doi.org/10.4000/abstractairanica.25352

Ce document a été généré automatiquement le 26 septembre 2020.

Tous droits réservés 


\title{
The military architecture of ancient Choresmia. Paris, de Boccard, 2006, 259 p. (Persika, 7)
}

\author{
Étienne de La Vaissière
}

1 Traduction anglaise (pp. 21-126) de la thèse de doctorat de l'A., directeur de l'archéologie de la branche Karakalpak de l'Académie des sciences ouzbèke, cet ouvrage comprend également un long appendice de A. Betts, qui dirige les fouilles australiennes au Khorezm, consacré aux rapports avec les nomades (pp. 131-155), ainsi qu'un imposant dossier d'illustrations (pp. 191-256). L'A. défend l'existence d'une école khorezmienne d'architecture militaire en raison de la complexité et du raffinement des fortifications (labyrinthes d'entrée, remparts creux, ouvrages avancés...). Il présente tout d'abord les sites, puis l'histoire du développement de cette tradition architecturale et enfin procède à des comparaisons avec les autres régions d'Asie centrale. Le texte a été doté par son traducteur, S. Helms, outre d'une introduction, de nombreuses et précieuses notes de bas de page qui complètent (avec des références occidentales mais aussi soviétiques) ou critiquent le texte principal. On ne saurait trop souligner l'utilité de ce volume pour donner accès à de multiples données sur l'histoire du Khorezm aux non-russophones. On notera cependant qu'il reste technique et ne prétend en rien proposer une histoire de l'urbanisation de la région.

\section{INDEX}

Thèmes : 3.1. Est de l'Iran 
AUTEURS

ÉTIENNE DE LA VAISSIÈRE

EPHE - Paris 